\title{
Multivariate Analysis of Vertical Jump Predicting Health-related Physical Fitness Performance
}

\author{
Peter D. Hart ${ }^{1,2, *}$ \\ ${ }^{1}$ Health Promotion Program, Montana State University - Northern, Havre, MT 59501 \\ ${ }^{2}$ Kinesmetrics Lab, Montana State University - Northern, Havre, MT 59501 \\ *Corresponding author: peter.hart@msun.edu
}

Received August 17, 2018; Revised September 29, 2018; Accepted October 06, 2018

\begin{abstract}
Background: Health-related fitness tests measure one of five different traits: cardiorespiratory endurance, muscular strength, muscular endurance, body composition, and flexibility. To assess an individual on all five traits can be costly and time consuming. Thus, it would be useful to the fitness practitioner if one single test could be used as a proxy for overall fitness. Therefore, the purpose of this study was to employ multivariate data analyses to examine the ability of the vertical jump (VJ) to predict health-related fitness performance. Methods: This study used data from college students who completed both ten different health-related fitness tests and the VJ assessment. Three body composition measures were used: percent body fat (PBF, \%), body mass index (BMI, $\mathrm{kg} / \mathrm{m}^{2}$ ), and waist circumference (WC, $\mathrm{cm}$ ). Four muscular fitness measures were used: 1RM bench press (BP, lb), 1RM leg press (LP, lb), maximal push-up repetition (PU, \#), and flexed arm hang time (FAH, sec). Two cardiorespiratory endurance measures were used: maximal oxygen consumption $(\mathrm{VO} 2, \mathrm{ml} / \mathrm{kg} / \mathrm{min})$ and physical activity rating score (PAR, 0 thru 10$)$. One flexibility measure was used: sit-and-reach (SNR, cm). The countermovement vertical jump (VJ, in) was used as the single predictor variable and participants were categorized into high or low VJ groups using the sex-specific median. Results: Male-specific multivariate analysis of variance (MANOVA) results showed that VJ significantly predicts the linear combination of body composition $(\lambda=0.85$, $\mathrm{F}=4.8, \mathrm{p}=.004)$, muscular fitness $(\lambda=0.66, \mathrm{~F}=10.4, \mathrm{p}<.001)$, and cardiorespiratory endurance $(\lambda=0.85, \mathrm{~F}=7.3, \mathrm{p}=.001)$. Female-specific MANOVA results also showed that VJ significantly predicts the linear combination of body composition $(\lambda=0.43, \mathrm{~F}=17.6, \mathrm{p}<.001)$, muscular fitness $(\lambda=0.41, \mathrm{~F}=14.1, \mathrm{p}<.001)$, and cardiorespiratory endurance $(\lambda=0.61, \mathrm{~F}=13.0, \mathrm{p}<.001)$. Univariate ANOVA models showed that VJ significantly predicts flexibility $(\mathrm{F}=5.0$, $\mathrm{p}=.028$ ) in males only. Overall fitness MANOVA models showed that VJ significantly predicts the linear combination of all ten fitness scores in both males $(\lambda=0.61, \mathrm{~F}=4.8, \mathrm{p}<.001)$ and females $(\lambda=0.33, \mathrm{~F}=6.8, \mathrm{p}<.001)$. Conclusion: Results from this study indicate that VJ is a valid predictor of health-related fitness performance in college students.
\end{abstract}

Keywords: physical fitness, vertical jump, multivariate analysis of variance (MANOVA)

Cite This Article: Peter D. Hart, "Multivariate Analysis of Vertical Jump Predicting Health-related Physical Fitness Performance." American Journal of Sports Science and Medicine, vol. 6, no. 4 (2018): 99-105. doi: 10.12691/ajssm-6-4-1.

\section{Introduction}

Health-related physical fitness is a set of attributes that relate to one's ability to perform physical tasks and that also relate to good health outcomes [1]. The specific health-related fitness attributes are: cardiorespiratory endurance, muscular strength, muscular endurance, body composition, and flexibility [2]. Other fitness attributes exist as well and are less so related to health outcomes and more so related to skills, such as those required in sports. These specific skill-related components are agility, balance, coordination, power, speed, and reaction time [3]. Although skill-related fitness traits are generally healthy and should be endorsed by most individuals, health-related fitness traits are supported by evidence [4,5,6,7] and therefore promoted to all adults $[8,9,10]$.

Despite our knowledge regarding the benefits associated with health-related fitness, there are still many barriers preventing adults from achieving optimal fitness. One such barrier is the difficult task of baseline and follow-up fitness assessment. For example, many adults may lack the knowledge, skill, resources, equipment, and/or motivation required to properly administer and evaluate a health-related fitness test [11]. Moreover, to assess overall health-related fitness, an adult would have to perform several different tests. Therefore, a need exists for a more parsimonious overall health-related fitness assessment. Thus, the purpose of this study was to examine the ability of a single test to predict component-specific and overall health-related fitness. An explosive jump test that involves 
ankle plantar flexor, knee extensor, hip extensor, and shoulder flexor/abductor muscles and is also simple to administer could in theory be such a test [12]. Specifically, multivariate statistical models were used in this study to determine if performance on a vertical jumping test could predict health-related fitness performance in college students.

\section{Methods}

\subsection{Participants and Design}

Data for this research came from a campus-based fitness assessment study where $\mathrm{N}=131$ male and female college students attending a public university volunteered to participate [13]. Students were included in this study if they completed all pertinent fitness assessments. Recruitment occurred by public flyers and word-of-mouth and students were offered free fitness evaluation in exchange for their participation. All study methods and procedures were reviewed and approved by the university system's institutional review board (IRB).

\subsection{Variables Utilized}

The dependent variables in this research were: percent body fat (PBF), body mass index (BMI), waist circumference (WC), one repetition maximum (1RM) bench press (BP), 1RM leg press (LP), maximal push-up repetition (PU), flexed arm hang time (FAH), maximal oxygen consumption (VO2), physical activity rating (PAR), and sit-and-reach length (SNR). The countermovement vertical jump (VJ) was the single predictor variable.

\subsection{Assessment of Fitness Tests}

PBF (\%) was assessed using the sum of three skinfold sites and sex-specific Jackson and Pollack density equations [14]. BMI $\left(\mathrm{kg} / \mathrm{m}^{2}\right)$ was assessed using a wall mounted stadiometer to measure participant height and a digital floor scale to measure weight [15]. WC (cm) was assessed using an elastic tape and measuring the narrowest point between the participant's umbilicus and xiphoid process [16]. BP (lb) and LP (lb) were assessed according to ACSM guidelines where the heaviest load successfully lifted was considered the 1RM [17]. PU was assessed using ACSM guidelines where the total number of pushup repetitions completed with proper form was the participant's score [14]. FAH (sec) was assessed by participants hanging from a pull-up bar with an underhand grip and elbows flexed with chin above the bar [18]. The total time the participant kept their chin above the bar without touching it was their FAH score.

VO2 (ml/kg/min) was assessed by a multi-stage running test where participants continually ran a 20 meter distance within a period bound by starting and ending audio beeps [19]. The VO2 test was stopped when the participant failed to reach a 20 meter mark before the ending beep twice in a row. PAR (0 thru 10) was assessed by a single response to a physical activity scenario describing the participant's overall level of activity [20]. PAR responses ranged from 0 (avoid walking or exertion) to 10 (run over 25 miles per week or equivalent). VJ (inches) was assessed by a countermovement jump off both legs with participants next to a wall with dominant hand extending up and marking the wall with chalked fingers [21]. VJ scores were computed as the differences between participant jump height (marked wall jump height) and pre-determined reach (marked wall standing reach height). Participants were categorized into high or low VJ groups using the sex-specific median VJ score.

\subsection{Statistical Analyses}

Descriptive statistics were computed for all study variables by sex. Sex-specific median VJ scores were used to create new high and low VJ performance values. To assess relationship between variables and check for multicollinearity, bivariate correlations were computed for all dependent variables by sex. Sex-specific MANOVA models were run first by health-related fitness component variables (i.e., body composition, muscular fitness, cardiorespiratory endurance). VJ performance was assessed for its ability to predict the linear combination of body composition variables (PBF, BMI, and WC), muscular fitness variables (BP, LP, PU, and FAH), and cardiorespiratory endurance variables (VO2 and PAR). The Wilks' Lambda $(\lambda)$ statistic was reported to determine the multivariate predictive ability of $\mathrm{VJ}$ performance. Follow-up univariate ANOVA models were run on each individual health-related fitness variable. ANOVA models were also run for the single flexibility variable (sit-and reach). Two sets of overall models were run to examine the ability of $\mathrm{VJ}$ in predicting overall health-related fitness performance. Sex-specific MANOVA models were run using all ten health-related fitness variables simultaneously. Finally, univariate ANOVA models were run to examine the potential of $\mathrm{VJ}$ in predicting an overall fitness score. Overall fitness scores were computed as an average sex-specific $\mathrm{T}$-score from all ten health-related fitness tests. All analyses were performed using SAS version 9.4 [22,23]. All p-values were reported as 2-sided and statistical significance was defined as $p$-values $<0.05$.

\section{Results}

Table 1 contains descriptive statistics of all study variables by sex. Mean sex differences were significant $(p s<.05)$ for all fitness variables. Males had larger mean values on all fitness tests except for PBF and SNR. Median VJ values were 23.5 in (for males) and 16.0 in (for females). Table 2 displays bivariate correlation coefficients between all dependent variables for both males (below the diagonal) and females (above the diagonal). No correlation coefficient exceeded .80, indicating that multicollinearity was not an issue in further analyses.

Table 3 and Table 4 display results for the MANOVA and ANOVA models. Male-specific MANOVA results showed that VJ significantly predicts the linear combination of body composition $(\lambda=0.85, F=4.8, p=.004)$, muscular fitness $(\lambda=0.66, \quad F=10.4, \quad p<.001)$, and cardiorespiratory endurance $(\lambda=0.85, F=7.3, p=.001)$. All follow-up ANOVA models reinforced male $\mathrm{VJ}$ as a 
significant predictor, except for LP $(F=0.1, p=.705)$. Female-specific MANOVA results also showed that VJ significantly predicts the linear combination of body composition $(\lambda=0.43, F=17.6, p<.001)$, muscular fitness $(\lambda=0.41, \quad F=14.1, \quad p<.001), \quad$ and cardiorespiratory endurance $(\lambda=0.61, \quad F=13.0, \quad p<.001)$. All follow-up ANOVA models reinforced female VJ as a significant predictor, except for LP $(F=0.2, p=.897)$ and BP $(F=2.3$, $p=.138)$. Univariate ANOVA models showed that VJ significantly predicts flexibility $(F=5.0, p=.028)$ in males only.
Table 5 contains results for the overall fitness MANOVA and ANOVA models. Overall fitness MANOVA models showed that VJ significantly predicts the linear combination of all ten fitness scores in both males $(\lambda=0.61, F=4.8$, $p<.001)$ and females $(\lambda=0.33, F=6.8, p<.001)$. Univariate ANOVA models showed that VJ significantly predicts overall fitness score for both males (Low VJ Mean $=47.2$ vs. High VJ Mean=52.8, $F=27.6, p<.001)$ and females (Low VJ Mean=45.2 vs. High VJ Mean=54.0, $F=38.7$, $p<.001)$. Figure 1 and Figure 2 display overall fitness score mean differences in males and females, respectively.

Table 1. Descriptive statistics of all study variables

\begin{tabular}{|c|c|c|c|c|c|}
\hline Variable & Mean & Median & $S D$ & Min & $\operatorname{Max}$ \\
\hline \multicolumn{6}{|c|}{ Male $(N=87)$} \\
\hline $\mathrm{VJ}$ (in) & 23.5 & 23.5 & 4.4 & 13.0 & 36.5 \\
\hline $\operatorname{PBF}(\%)$ & 13.9 & 12.4 & 6.7 & 4.4 & 31.2 \\
\hline BMI $\left(\mathrm{kg} / \mathrm{m}^{2}\right)$ & 27.7 & 27.0 & 4.6 & 20.8 & 41.6 \\
\hline $\mathrm{WC}(\mathrm{cm})$ & 86.6 & 84.0 & 9.6 & 71.5 & 122.0 \\
\hline $\mathrm{BP}(\mathrm{lb})$ & 232.0 & 225.0 & 67.4 & 31.5 & 450.0 \\
\hline LP (lb) & 593.5 & 550.0 & 166.2 & 270.0 & 900.0 \\
\hline PU (\#) & 35.4 & 32.0 & 16.0 & 8.0 & 83.0 \\
\hline FAH (sec) & 33.8 & 32.0 & 18.9 & 0.0 & 90.0 \\
\hline VO2 (ml/kg/min) & 36.9 & 35.8 & 8.1 & 20.2 & 57.5 \\
\hline PAR (0 thru 10) & 6.7 & 7.0 & 2.5 & 2.0 & 10.0 \\
\hline $\mathrm{SNR}(\mathrm{cm})$ & 29.0 & 29.0 & 8.9 & 9.0 & 49.0 \\
\hline \multicolumn{6}{|c|}{ Female $(N=44)$} \\
\hline VJ (in) & 15.2 & 16.0 & 3.7 & 6.0 & 23.5 \\
\hline $\operatorname{PBF}(\%)$ & 23.2 & 23.1 & 5.2 & 14.5 & 34.6 \\
\hline BMI $\left(\mathrm{kg} / \mathrm{m}^{2}\right)$ & 24.4 & 23.9 & 3.5 & 18.8 & 33.2 \\
\hline $\mathrm{WC}(\mathrm{cm})$ & 75.0 & 72.7 & 8.2 & 60.0 & 94.0 \\
\hline $\mathrm{BP}(\mathrm{lb})$ & 95.6 & 95.0 & 23.6 & 45.0 & 155.0 \\
\hline $\mathrm{LP}(\mathrm{lb})$ & 321.3 & 320.0 & 110.2 & 70.0 & 585.0 \\
\hline PU (\#) & 26.2 & 25.0 & 11.1 & 2.0 & 45.0 \\
\hline FAH (sec) & 25.0 & 21.5 & 19.7 & 0.0 & 73.0 \\
\hline $\mathrm{VO} 2(\mathrm{ml} / \mathrm{kg} / \mathrm{min})$ & 30.6 & 30.3 & 7.4 & 18.1 & 47.3 \\
\hline PAR (0 thru 10) & 5.5 & 6.0 & 2.8 & 1.0 & 10.0 \\
\hline $\mathrm{SNR}(\mathrm{cm})$ & 34.4 & 34.3 & 8.0 & 17.0 & 50.0 \\
\hline
\end{tabular}

Note. VJ is vertical jump. PBF is percent body fat. BMI is body mass index. WC is waist circumference. BP is bench press. LP is leg press. PU is pushup. FAH is flexed arm hang. VO2 is oxygen consumption. PAR is physical activity rating. SNR is sit-and-reach. Significant (ps<.05) mean sex differences were seen on all variables.

Table 2. Correlation matrix of all dependant variables for males (bottom) and females (top)

\begin{tabular}{|c|c|c|c|c|c|c|c|c|c|c|}
\hline Variable & $\mathrm{PBF}$ & BMI & WC & $\mathrm{BP}$ & LP & PU & FAH & VO2 & PAR & SNR \\
\hline $\operatorname{PBF}(\%)$ & 1 & .676 & .508 & -.314 & -.118 & -.270 & -.708 & -.655 & -.495 & -.066 \\
\hline BMI $\left(\mathrm{kg} / \mathrm{m}^{2}\right)$ & .770 & 1 & .827 & .118 & .304 & -.221 & -.665 & -.495 & -.262 & .061 \\
\hline $\mathrm{WC}(\mathrm{cm})$ & .677 & .799 & 1 & .020 & .324 & -.372 & -.570 & -.353 & -.188 & .078 \\
\hline $\mathrm{BP}(\mathrm{lb})$ & .069 & .337 & .258 & 1 & .564 & .584 & .262 & .479 & .523 & .516 \\
\hline $\mathrm{LP}(\mathrm{lb})$ & .268 & .518 & .555 & .573 & 1 & .211 & .177 & .221 & .281 & .347 \\
\hline PU (\#) & -.475 & -.238 & -.311 & .425 & .148 & 1 & .386 & .433 & .468 & .238 \\
\hline FAH (sec) & -.629 & -.593 & -.607 & .024 & -.186 & .498 & 1 & .611 & .471 & .196 \\
\hline $\mathrm{VO} 2(\mathrm{ml} / \mathrm{kg} / \mathrm{min})$ & -.551 & -.509 & -.546 & .062 & -.194 & .381 & .380 & 1 & .764 & .229 \\
\hline PAR (0 thru 10) & -.443 & -.389 & -.286 & .155 & -.104 & .514 & .390 & .421 & 1 & .334 \\
\hline $\mathrm{SNR}(\mathrm{cm})$ & -.249 & -.026 & -.162 & .296 & .145 & .416 & .252 & .266 & .250 & 1 \\
\hline
\end{tabular}

Note. $N=87$ for males (below the diagonal). $\mathrm{N}=44$ for females (above the diagonal). VJ is vertical jump. PBF is percent body fat. BMI is body mass index. WC is waist circumference. BP is bench press. LP is leg press. PU is push-up. FAH is flexed arm hang. VO2 is oxygen consumption. PAR is physical activity rating. SNR is sit-and-reach. Bold values are significant $(p<.05)$. 
Table 3. MANOVA and univariate ANOVA results for VJ predicting fitness in males

\begin{tabular}{|c|c|c|c|c|c|c|}
\hline \multirow[b]{2}{*}{ Variable } & \multicolumn{2}{|c|}{ Low VJ $(N=44)$} & \multicolumn{2}{|c|}{ High VJ $(N=43)$} & \multicolumn{2}{|c|}{ ANOVA } \\
\hline & Mean & $S D$ & Mean & $S D$ & $p$ & $p^{\prime}$ \\
\hline \multicolumn{7}{|l|}{ Body Composition } \\
\hline $\operatorname{PBF}(\%)$ & 16.0 & 7.7 & 11.7 & 4.9 & .003 & .003 \\
\hline BMI $\left(\mathrm{kg} / \mathrm{m}^{2}\right)$ & 28.7 & 5.5 & 26.7 & 3.4 & .037 & .037 \\
\hline $\mathrm{WC}(\mathrm{cm})$ & 89.7 & 10.9 & 83.5 & 6.7 & .002 & .002 \\
\hline MANOVA & \multicolumn{4}{|c|}{ Wilks' Lambda $=0.85, \mathrm{~F}(3,83)=4.84, p=.004$} & & \\
\hline \multicolumn{7}{|l|}{ Muscular Fitness } \\
\hline $\mathrm{BP}(\mathrm{lb})$ & 206.3 & 66.9 & 258.3 & 57.7 & $<.001$ & $<.001$ \\
\hline LP (lb) & 600.2 & 161.5 & 586.6 & 172.5 & .705 & .705 \\
\hline PU (\#) & 28.3 & 11.8 & 42.7 & 16.5 & $<.001$ & $<.001$ \\
\hline $\mathrm{FAH}(\mathrm{sec})$ & 28.6 & 22.1 & 39.0 & 13.3 & .010 & .010 \\
\hline MANOVA & \multicolumn{4}{|c|}{ Wilks' Lambda $=0.66, \mathrm{~F}(4,82)=10.36, p<.001$} & & \\
\hline \multicolumn{7}{|c|}{ Cardiorespiratory Endurance } \\
\hline $\operatorname{VO} 2(\mathrm{ml} / \mathrm{kg} / \mathrm{min})$ & 34.2 & 8.1 & 39.6 & 7.1 & .002 & .002 \\
\hline PAR (0 thru 10) & 5.9 & 2.5 & 7.5 & 2.3 & .003 & .003 \\
\hline MANOVA & \multicolumn{4}{|c|}{ Wilks' Lambda $=0.85, \mathrm{~F}(2,84)=7.28, p=.001$} & & \\
\hline \multicolumn{7}{|l|}{ Flexibility } \\
\hline SNR (cm) & 26.93182 & 9.992783 & 31.09302 & 7.088099 & .028 & .028 \\
\hline
\end{tabular}

Note. $N=87$. VJ is vertical jump. $\mathrm{PBF}$ is percent body fat. BMI is body mass index. WC is waist circumference. $\mathrm{BP}$ is bench press. LP is leg press. $\mathrm{PU}$ is push-up. FAH is flexed arm hang. VO2 is oxygen consumption. PAR is physical activity rating. SNR is sit-and-reach. ANOVA $p$ is for one-way univariate ANOVA. ANOVA $p$ ' is for one-way univariate Welch's ANOVA.

Table 4. MANOVA and univariate ANOVA results for VJ predicting fitness in females

\begin{tabular}{|c|c|c|c|c|c|c|}
\hline \multirow[b]{2}{*}{ Variable } & \multicolumn{2}{|c|}{ Low VJ $(N=20)$} & \multicolumn{2}{|c|}{ High VJ $(N=24)$} & \multicolumn{2}{|c|}{ ANOVA } \\
\hline & Mean & $S D$ & Mean & $S D$ & $p$ & $p^{\prime}$ \\
\hline \multicolumn{7}{|l|}{ Body Composition } \\
\hline $\operatorname{PBF}(\%)$ & 27.2 & 4.0 & 19.9 & 3.6 & $<.001$ & $<.001$ \\
\hline $\operatorname{BMI}\left(\mathrm{kg} / \mathrm{m}^{2}\right)$ & 26.9 & 3.3 & 22.3 & 1.9 & $<.001$ & $<.001$ \\
\hline $\mathrm{WC}(\mathrm{cm})$ & 80.2 & 8.8 & 70.6 & 4.1 & $<.001$ & $<.001$ \\
\hline MANOVA & \multicolumn{4}{|c|}{ Wilks' Lambda $=0.43, \mathrm{~F}(3,40)=17.62, p<.001$} & & \\
\hline \multicolumn{7}{|l|}{ Muscular Fitness } \\
\hline $\mathrm{BP}(\mathrm{lb})$ & 89.8 & 28.5 & 100.4 & 17.8 & .138 & .157 \\
\hline LP (lb) & 319.0 & 130.0 & 323.3 & 93.3 & .897 & .900 \\
\hline PU (\#) & 22.5 & 12.0 & 29.3 & 9.4 & .041 & .047 \\
\hline FAH (sec) & 9.1 & 8.3 & 38.4 & 16.0 & $<.001$ & $<.001$ \\
\hline MANOVA & \multicolumn{4}{|c|}{ Wilks' Lambda $=0.41, \mathrm{~F}(4,39)=14.11, p<.001$} & & \\
\hline \multicolumn{7}{|c|}{ Cardiorespiratory Endurance } \\
\hline VO2 (m1/kg/min) & 25.6 & 5.8 & 34.7 & 5.9 & $<.001$ & $<.001$ \\
\hline PAR (0 thru 10) & 4.2 & 2.7 & 6.7 & 2.4 & .002 & .003 \\
\hline MANOVA & \multicolumn{4}{|c|}{ Wilks' Lambda $=0.61, \mathrm{~F}(2,41)=13.03, p<.001$} & & \\
\hline \multicolumn{7}{|l|}{ Flexibility } \\
\hline $\mathrm{SNR}(\mathrm{cm})$ & 33.8 & 8.8 & 34.8 & 7.4 & .687 & .692 \\
\hline
\end{tabular}

Note. $N=44$. VJ is vertical jump. $\mathrm{PBF}$ is percent body fat. BMI is body mass index. $\mathrm{WC}$ is waist circumference. $\mathrm{BP}$ is bench press. $\mathrm{LP}$ is leg press. $\mathrm{PU}$ is push-up. FAH is flexed arm hang. VO2 is oxygen consumption. PAR is physical activity rating. SNR is sit-and-reach. ANOVA $p$ is for one-way univariate ANOVA. ANOVA $p$ ' is for one-way univariate Welch's ANOVA. 
Table 5. MANOVA and univariate ANOVA results for $\mathrm{VJ}$ predicting overall fitness

\begin{tabular}{|c|c|c|c|c|c|c|}
\hline \multirow[b]{2}{*}{ Variable } & \multicolumn{2}{|c|}{ Low VJ } & \multicolumn{2}{|c|}{ High VJ } & \multicolumn{2}{|c|}{ ANOVA } \\
\hline & Mean & $S D$ & Mean & $S D$ & $p$ & $p^{\prime}$ \\
\hline \multicolumn{7}{|l|}{ Male } \\
\hline Overall $(\mathrm{T})$ & 47.2 & 5.8 & 52.8 & 4.1 & $<.001$ & $<.001$ \\
\hline MANOVA & \multicolumn{4}{|c|}{ Wilks' Lambda $=0.61, \mathrm{~F}(10,76)=4.78, p<.001$} & & \\
\hline \multicolumn{7}{|l|}{ Female } \\
\hline Overall (T) & 45.2 & 5.8 & 54.0 & 3.4 & $<.001$ & $<.001$ \\
\hline MANOVA & \multicolumn{4}{|c|}{ Wilks' Lambda $=0.33, \mathrm{~F}(10,33)=6.77, p<.001$} & & \\
\hline
\end{tabular}

Note. Overall fitness scores were computed as the average sex-specific T-score from each of the 10 fitness tests. MANOVA tests used all 10 fitness tests as dependant variables. ANOVA $p$ is for one-way univariate ANOVA. ANOVA $p$ ' is for one-way univariate Welch's ANOVA

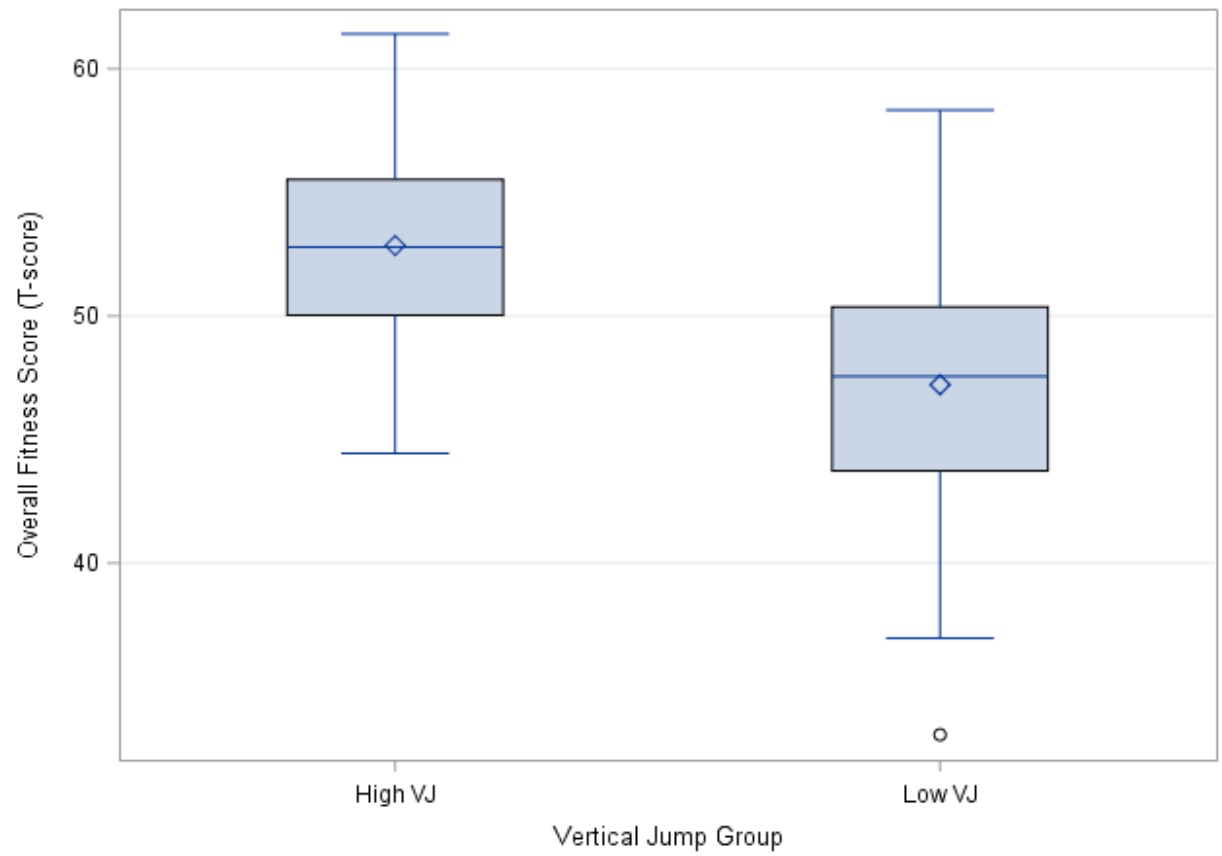

Figure 1. Box plots showing results for VJ predicting overall fitness in males (Note. $N=87$. Plot displays significant mean difference $(p<.05)$ )

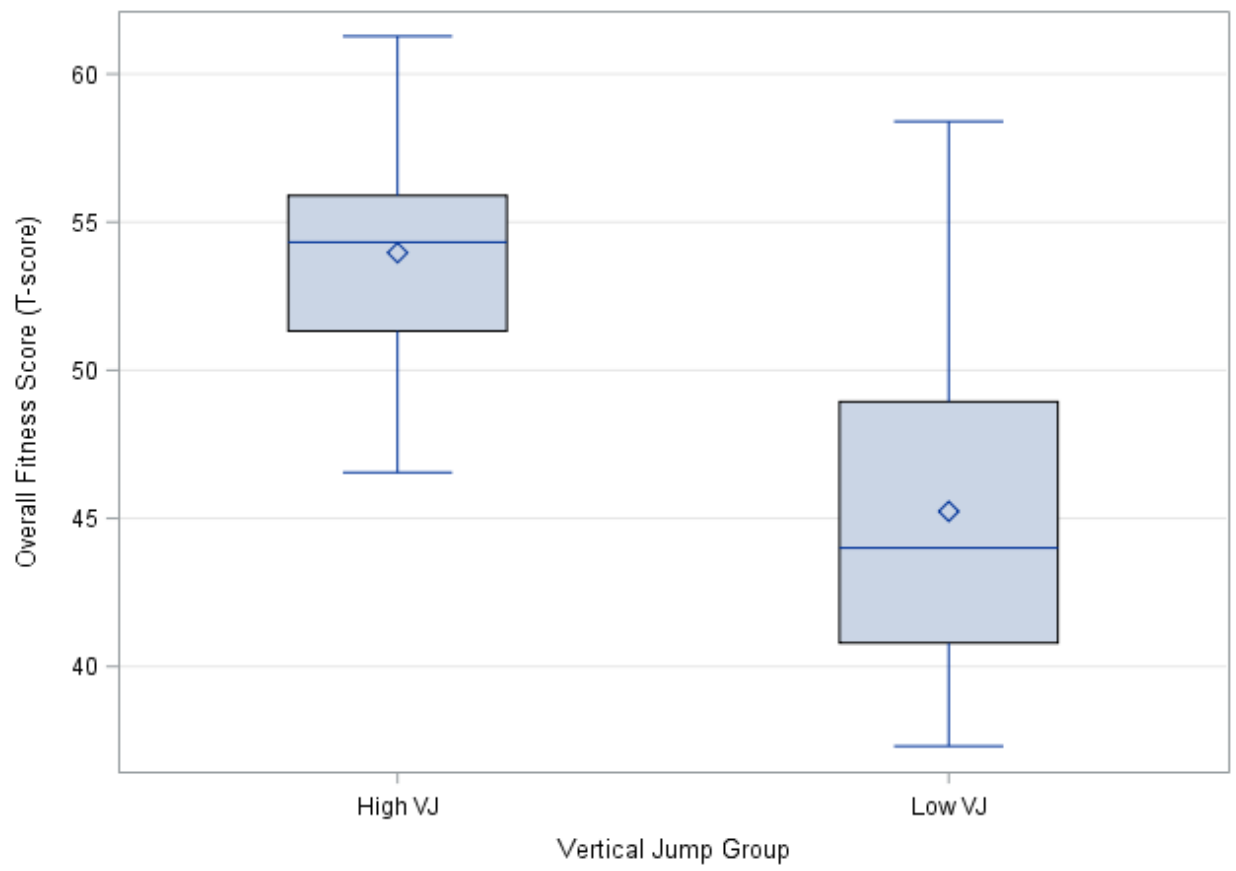

Figure 2. Box plots showing results for VJ predicting overall fitness in females (Note. $N=44$. Plot displays significant mean difference $(p<.05)$ ) 


\section{Discussion}

The purpose of this study was to examine the ability of a single test to predict specific and overall health-related fitness. More specifically, the aim was to use multivariate statistical models to determine if the VJ test could predict health-related fitness performance in college students. The study results showed that VJ could indeed predict health-related fitness performance in both males and females. Furthermore, multivariate models indicated that VJ could significantly predict body composition, muscular fitness, and cardiorespiratory endurance in both males and females. Additionally, multivariate models that included all ten fitness variables indicated that VJ could significantly predict overall health-related fitness in both males and females. These results are not without their caveats. For example, among females, SNR was not significantly predicted by VJ. This, however, is not surprising - since females genetically have better flexibility than males, despite their level of fitness [24]. Another caveat worth mentioning is the fact that follow-up univariate analyses indicated that VJ did not significantly predict LP in both males and females and did not significantly predict BP in females. Although these non-significant findings are worth bearing in mind, the power of the employed multivariate analysis is that the independent variable is assessed for its ability to predict the linear combination of the dependent variables. In other words, VJ significantly predicted performance on all four muscular fitness tests combined as they represent the theoretical muscular fitness construct [25]. Therefore, VJ can be used as a fitness proxy for body composition, muscular fitness, cardiorespiratory endurance, as well as overall healthrelated fitness in both male and female college students.

The implications of these findings are vast. As previously mentioned, one barrier that may prevent adults from attaining higher levels of health-related fitness, is the difficulty involved in baseline and follow-up fitness assessment. Results from this study show, however, that a simple VJ test can be administered and used to evaluate overall health-related fitness. The simplicity of the VJ test (requiring only chalk, a measuring device, and wall with high ceilings) reinforces that anyone can administer it safely by themselves.

The current study is not without limitations. The most significant limitation is the fact that this study only used college students for participants. Although college students are generally considered adults, they are also generally considered healthier than other age groups [26]. Therefore, the external validity of these findings should be considered when contemplating the ability of the VJ to predict health-related fitness in other populations. An additional limitation in this study is its use of field tests to measure health-related fitness. Although field tests on a large sample of college students was the most practical course, lab-based tests of body composition, muscular fitness, and cardiorespiratory endurance may provide increased reliability in study measures - and therefore should be considered when interpreting these results.

\section{Conclusions}

Results from this study indicate that $\mathrm{VJ}$ is a valid predictor of body composition, muscular fitness, cardiorespiratory endurance, and overall health-related fitness performance in college students. Researchers and practitioners should consider promoting the VJ as a simple, safe, and efficient proxy for health-related fitness performance.

\section{Acknowledgements}

No financial assistance was used to assist with this project.

\section{References}

[1] American College of Sports Medicine, editor. ACSM's healthrelated physical fitness assessment manual. Lippincott Williams \& Wilkins. 2013.

[2] Ganley, K. J., Paterno, M. V., Miles, C., Stout, J., Brawner, L., Girolami, G., \& Warren, M. (2011). Health-related fitness in children and adolescents. Pediatric Physical Therapy, 23(3), 208-220.

[3] Nindl, B. C., Alvar, B. A., Dudley, J. R., Favre, M. W., Martin, G. J., Sharp, M. A., ... \& Kraemer, W. J. (2015). Executive summary from The National strength and conditioning association's second blue ribbon panel on military physical readiness: military physical performance testing. The Journal of Strength \& Conditioning Research, 29, S216-S220.

[4] Clausen, J. S., Marott, J. L., Holtermann, A., Gyntelberg, F., \& Jensen, M. T. (2018). Midlife Cardiorespiratory Fitness and the Long-Term Risk of Mortality: 46 Years of Follow-Up. Journal of the American College of Cardiology, 72(9), 987-995.

[5] Prasitsiriphon, O., \& Pothisiri, W. (2018). Associations of Grip Strength and Change in Grip Strength With All-Cause and Cardiovascular Mortality in a European Older Population. Clinical Medicine Insights: Cardiology, 12, 1179546818771894.

[6] Abramowitz, M. K., Hall, C. B., Amodu, A., Sharma, D., Androga, L., \& Hawkins, M. (2018). Muscle mass, BMI, and mortality among adults in the United States: A population-based cohort study. PloS One, 13(4), e0194697.

[7] Hart, P. D. (2018). Concurrent Relationship of Objectively Measured Physical Activity and Cardiorespiratory Fitness on Two Different Measures of Obesity in U.S. Adults. Journal of Physical Activity Research, 3(2): 78-81.

[8] Oja, P., \& Tuxworth, B. (Eds.). (1995). Eurofit for adults: Assessment of health-related fitness. Council of Europe.

[9] Suni, J., Husu, P., \& Rinne, M. (2009). Fitness for health: the ALPHA-FIT test battery for adults aged 18-69. Tester's Manual. Tampare, Finland: Published by European Union DS, and the UKK Institute for Health Promotion Research.

[10] Physical Activity Guidelines Advisory Committee. (2008). Physical activity guidelines advisory committee report, 2008. Washington, DC: US Department of Health and Human Services, 2008, A1-H14.

[11] Morrow Jr, J. R., Mood, D., Disch, J., \& Kang, M. (2015). Measurement and Evaluation in Human Performance, 5E. Human Kinetics.

[12] Lees, A., Vanrenterghem, J., \& De Clercq, D. (2004). Understanding how an arm swing enhances performance in the vertical jump. Journal of biomechanics, 37(12), 1929-1940.

[13] Hart, P. D., Benavidez, G., Detomasi, N., Potter, A., Rech, K., Budak, C., Faupel, N., Thompson, J., Schwenke, L., Jericoff, G., Manuel, M., Lee, T., Edmonson, W., Auzenne, C., Kirkaldie, T., Lonebear, M., \& Miller, L. (2017). A multitrait-multimethod (MTMM) study of fitness assessments in college students. SM Journal of Sports Medicine and Therapy. 1(1): 1002.

[14] American College of Sports Medicine. (2018). ACSM's guidelines for exercise testing and prescription. Lippincott Williams \& Wilkins.

[15] Raven P, Wasserman D, Squires W, Murray T. Exercise Physiology. Nelson Education. 2012.

[16] American College of Sports Medicine. ACSM's Resources for the Exercise Physiologist, 2nd. Philadelphia, Md.: Lippincott Williams \& Wilkins. 2017. 
[17] American College of Sports Medicine. (2012). ACSM's resource manual for guidelines for exercise testing and prescription. Lippincott Williams \& Wilkins.

[18] Welk, G. J., \& Meredith, M. D. Fitnessgram/Activitygram Reference Guide. 2008. Dallas, TX: The Cooper Institute.

[19] Ramsbottom R, Brewer J, Williams C. A Progressive Shuttle Run Test to Estimate Maximal Oxygen Uptake. Br Sports Med. 1988; 22: 141-144.

[20] George, J. D., Stone, W. J., \& Burkett, L. N. (1997). Non-exercise VO2max estimation for physically active college students. Medicine and science in sports and exercise, 29(3), 415-423.

[21] Haff, G. G., \& Triplett, N. T. (Eds.). (2015). Essentials of strength training and conditioning 4 th edition. Human kinetics.
[22] Tabachnick, B. G., \& Fidell, L. S. (2007). Using multivariate statistics. Allyn \& Bacon/Pearson Education.

[23] Cody, R. P., \& Smith, J. K. (2006). Applied Statistics \& SAS Programming. Prentice Hall.

[24] Cech, D. J., \& Martin, S. T. (2011). Functional Movement Development Across the Life Span-E-Book. Elsevier Health Sciences.

[25] Licht, M. H., Grimm, L. G., \& Yarnold, P. R. (1995). Reading and understanding multivariate statistics. Washington DC, American Psychological Association.

[26] Hart, P. D. (2017). Physical Activity and Health-Related Quality of Life in Rural Adults with Chronic Disease. American Journal of Medical Sciences and Medicine, 5(3): 62-66. 